\title{
Plant defense responses triggered by phytoseiid predatory mites (Mesostigmata: Phytoseiidae) are species-specific, depend on plant genotype and may not be related to direct plant feeding
}

\author{
Joaquín Cruz-Miralles (i) Marc Cabedo-López $(\mathbb{D} \cdot$ Michela Guzzo (i) \\ Meritxell Pérez-Hedo $\mathbb{D} \cdot$ Víctor Flors $\mathbb{i} \cdot$ Josep A. Jaques $\mathbb{C}$
}

Received: 30 July 2020 / Accepted: 7 January 2021 / Published online: 25 January 2021

(C) The Author(s) 2021

\begin{abstract}
Zoophytophagous arthropods can elicit plant defense responses affecting potential prey beyond predation. Phytophagy prevails as the main trigger for these responses, as in the case of Euseius stipulatus (Athias-Henriot) (Mesostigmata: Phytoseiidae), a predator occurring in citrus. Because other triggers cannot be excluded, our aim was to examine whether other phytoseiids co-occurring with E. stipulatus but not engaged in plant feeding [Neoseiulus californicus (McGregor) and Phytoseiulus persimilis Athias-Henriot] could induce similar responses (in
\end{abstract}

Handling Editor: Dirk Babendreier.

Supplementary Information The online version contains supplementary material available at https://doi.org/10.1007/ s10526-021-10077-8.

J. Cruz-Miralles · M. Cabedo-López ·

M. Guzzo · M. Pérez-Hedo · J. A. Jaques $(\bowtie)$

Departament de Ciències Agràries i del Medi Natural, Universitat Jaume I (UJI), Castelló de la Plana, Spain

e-mail: josep.jaques@camn.uji.es

Present Address:

M. Pérez-Hedo

Centro de Protección Vegetal y Biotecnología, Instituto

Valenciano de Investigaciones Agrarias (IVIA),

Montcada, Spain

V. Flors

Departament de Ciències Agràries i del Medi Natural, Integración Metabólica y Señalización Celular,

Universitat Jaume I (UJI), Castelló de la Plana, Spain terms of herbivore induced plant volatiles, HIPVs, and main defensive pathways), and how these affected the behavior of conspecifics and the shared prey, Tetranychus urticae Koch (Prostigmata: Tetranychidae). N. californicus triggered plant genotype-specific defense responses, including the production of different HIPVs compared to clean plants. However, we could not observe these effects for $P$. persimilis. T. urticae avoided better protected plants, because of stronger direct or indirect defense. As plants with weaker direct defense levels should offer higher prey densities, and those harboring conspecific predators represent higher risk of cannibalism, predators were expected to behave similarly. However, they did not. Our results demonstrate that plant defense triggered by phytoseiids is species-specific, depend on plant genotype and can be triggered by non-feeding activities. As $N$. californicus is a highly efficient predator used worldwide, further studies with this species are needed. Likewise, cineol, one of the volatiles identified in the blends triggered by this phytoseiid, could be used to manipulate the prey. These studies could pave the way for a more efficient use of phytoseiids in agroecosystems.

Keywords HIPV · Induced plant defense · Neoseiulus californicus · Phytoseiulus persimilis . Tetranychus urticae $\cdot$ Zoophytophagy 


\section{Introduction}

Zoophytophagous insects can trigger plant defense responses which may affect their prey beyond predation (De Puysseleyr et al. 2011; Messelink et al. 2015; Pappas et al. 2015; Perdikis et al. 2011). Phytophagy is considered the most common trigger for these responses. However, other triggers including oviposition, excretion and walking have been described (Hilker and Fatouros 2015; Hilker and Meiners 2010; Karban 2019; Schuman and Baldwin 2016; Wu and Baldwin 2010). Cruz-Miralles et al. (2019) demonstrated that similar to zoophytophagous insects, a phytoseiid mite can induce this type of responses. The omnivorous predator Euseius stipulatus (AthiasHenriot) (Acari: Mesostigmata), can elicit genotypedependent defense responses in Citrus spp. The jasmonic acid (JA), the salicylic acid (SA), and the flavonoids defense pathways were upregulated in sour orange (SO), Citrus aurantium L., while the JA- and the flavonoids-dependent signaling were upregulated and downregulated, respectively, in Cleopatra mandarin (CM), C. reshni hort. ex Tan., when infested by this phytoseiid (Cruz-Miralles et al. 2019). These two Citrus species had been chosen because of their extreme resistance and susceptibility to the herbivorous mite Tetranychus urticae Koch (Acari: Prostigmata), respectively (Agut et al. 2014; Bruessow et al. 2010), a potential prey for E. stipulatus (Ferragut et al. 1988; Pérez-Sayas et al. 2015). Different volatile blends (herbivore induced plant volatiles, HIPVs) were also induced in these Citrus species when exposed to E. stipulatus. These blends were exploited by this phytoseiid to select less defended plants, where higher prey densities could be expected, and did not inhibit T. urticae from choosing E. stipulatus-infested plants. Remarkably, in the same study the odors of $E$. stipulatus alone proved repellent to T. urticae.

Phytophagy prevails as the most likely cause for the observed plant responses to E. stipulatus as this is a zoophytophagous mite (Cruz-Miralles et al. 2021). However, as mentioned earlier other potential triggers cannot be excluded. E. stipulatus co-occurs in Spanish citrus orchards with other phytoseiids preying on $T$. urticae as well (Aguilar-Fenollosa et al. 2011; PérezSayas et al. 2015; Vela et al. 2017); among them, Neoseiulus californicus (McGregor), which can also feed on both prey and plant-derived food (i.e., pollen) (McMurtry and Croft 1997; McMurtry et al. 2013), and the Tetranychus sp.-specialist Phytoseiulus persimilis Athias-Henriot. None of these species, though, can directly feed on SO and CM plants (Cruz-Miralles et al. 2021). These differences offer the opportunity to check whether the plant responses to E. stipulatus are widespread among phytoseiids associated with Citrus spp., and, therefore, could be triggered not only by herbivory. Moreover, this system also allows checking whether $N$. californicus and $P$. persimilis may select the two aforementioned Citrus species in a similar way to E. stipulatus. Although, as pointed out earlier, predators would benefit from choosing less defended plants as indicative of higher prey densities, this was not always the case when testing herbivore-free plants. When the three phytoseiids were offered uninfested plants, they preferred better protected SO to $\mathrm{CM}$ plants, and this was attributed to predators interpreting higher basal defense (JA and SA) in SO as a sign of infestation (Cabedo-López et al. 2019). Interestingly, CM was less attractive to T. urticae following HIPVsinduced resistance (Agut et al. 2015), whereas the phytoseiid $P$. persimilis did not exhibit any preference for induced plants (Cabedo-López et al. 2019) and the other two phytoseiids preferred again better protected plants (i.e., induced rather than clean CM plants). These results highlight the complex interplay between plant and herbivore-derived scents on phytoseiid olfactory choices.

Our initial hypotheses are that (1) neither $N$. californicus nor $P$. persimilis will trigger defense responses in citrus as they do not directly feed on plants and (2) to avoid predation/cannibalism risk, both prey and predators will prefer clean versus phytoseiid-infested plants. Should our first hypothesis prove correct, phytophagy would stand as the most likely cause for the observed responses in E. stipulatus. To challenge these hypotheses, we have characterized the behavior of $T$. urticae, $N$. californicus, and $P$. persimilis in different $\mathrm{Y}$-tube olfactory tests. We have further characterized the volatile blends produced by these plants when exposed to phytoseiids, as well as the genetic changes in their main defensive pathways. 


\section{Materials and methods}

Plant material

Three-month-old pesticide-free SO and CM plants (about ten true leaves present) were used in our assays. Plants were grown from seed on vermiculite and peat in $320 \mathrm{ml}$ pots in a climatic chamber at $22 \pm 5{ }^{\circ} \mathrm{C}$, $60 \pm 10 \% \mathrm{RH}$ and L:D 16:8 photoperiod (same environmental conditions as for mite rearing and experiments below). Pesticide-free lemons and bean plants (Phaseolus vulgaris L. cv. Buenos Aires roja) were used to maintain $T$. urticae and phytoseiid colonies, respectively. Typha sp. pollen was used to feed phytoseiids.

\section{Spider mite stock colony}

This colony was initiated with specimens collected in clementine orchards close to our campus in 2001. To avoid maternal effects that could render the offspring phenotype better suited to its future host (Freinschlag and Schausberger 2016), spider mites used in the olfactory test were reared on lemons following CruzMiralles et al. (2019). In short, between eight and ten lemons were set on top of a wooden structure placed in an open plastic box $(40 \times 30 \times 8 \mathrm{~cm})$ half-filled with water. The wooden structure maintained the lemons above the water, which prevented mites escaping from the rearing. Lemons were replaced weekly in groups of four.

\section{Phytoseiid stock colonies}

Phytoseiulus persimilis was originally collected in 2012 in a citrus orchard close to our campus. Since then, colonies of this species have been maintained on rearing units using standard protocols (Pina et al. 2012). Basically, they consist of bean leaflets placed on a water-saturated sponge in a plastic tray with water. A mix of different stages of $T$. urticae was provided twice a week as food. $N$. californicus was regularly obtained from Koppert Biological Systems (SPICAL ${ }^{\circledR}$ ) and a small colony was established on bean leaflets following the same procedure as for $P$. persimilis. For this phytoseiid, Typha sp. pollen was also provided twice a week.
Y-tube olfactory choice assays

Different two-choice experiments involving T. urticae, N. californicus and P. persimilis, which were exposed to the body odors of the two phytoseiids and those of $\mathrm{SO}$ and $\mathrm{CM}$ plants in different combinations (see Figs. 1, 2) were performed using a Y-tube olfactometer (Bruin et al. 1992) as in previous work (Agut et al. 2014; Cruz-Miralles et al. 2019; CabedoLópez et al. 2019). Two of the Y-tube arms were directly connected via a plastic pipeline to the outlets of two identical 51 glass vessels (Duran, Mainz, Germany) containing different odor sources (i.e., nothing, a mesh bag containing 25 gravid phytoseiid females, or a citrus plant either clean or infested with 25 gravid phytoseiid females). Each vessel was connected to an air pump that produced a unidirectional airflow of $1.5 \mathrm{l} \mathrm{h}^{-1}$. The air was purified with a granular activated charcoal filter (Sigma-Aldrich). To remove any traces of food or carrier from the bodies of the gravid females allowed to make a choice, they were moved from the original substrate (the stock colonies for $T$. urticae and $P$. persimilis and the commercial vials for $N$. californicus) with a softbristle paintbrush to an arena consisting of a thin black plastic board $(9.5 \mathrm{~cm}$ diameter) placed on top of a water-saturated foam cube (3-4 cm thick) in an open plastic box $(20 \times 15 \times 4 \mathrm{~cm})$ half-filled with water to prevent mites escaping from the arena. Then, females were further moved into $50 \mathrm{ml}$ plastic vials (eight females per vial) containing a water-soaked cotton ball as water supply, where they were starved for $24 \mathrm{~h}$. Subsequently, they were individually deposited at the beginning of the base of the Y-wire using a soft-bristle paintbrush. They were allowed to make a choice between the two odors sources. Mites failing to reach either end of the arms within 10 min were scored as 'no choice'. After five females had been tested, the glass vessels were switched and after every ten females had been tested, the odor sources (i.e., the mesh bag or the plant) were replaced and the whole system was rinsed with ethanol (70\%), followed by air drying. Four sets of ten responding mites per species and choice combination were considered. To avoid pseudoreplication, each set was run at different dates. Plants and mites were discarded after use. To exclude any bias from the set-up, before the beginning of the assays, ten mites were exposed to clean air in both arms. A random response was expected and 


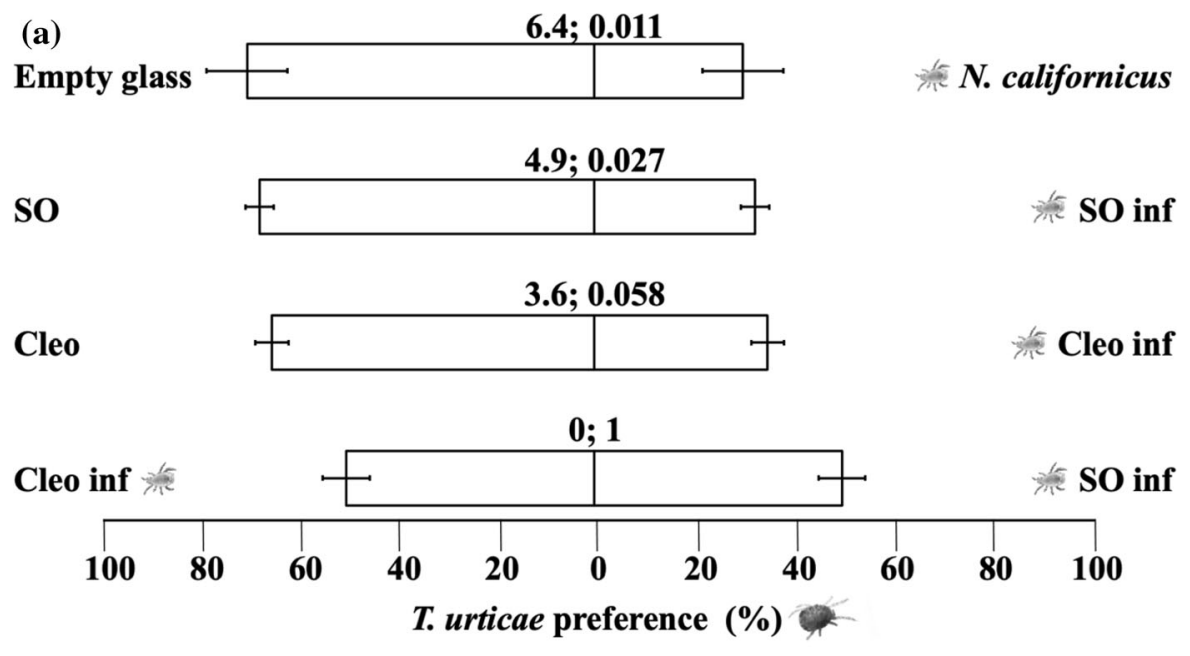

(b)

Empty glass

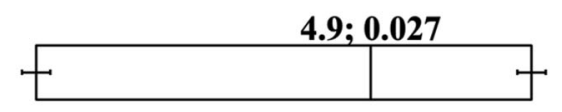

P. persimilis

SO

4.9;0.027

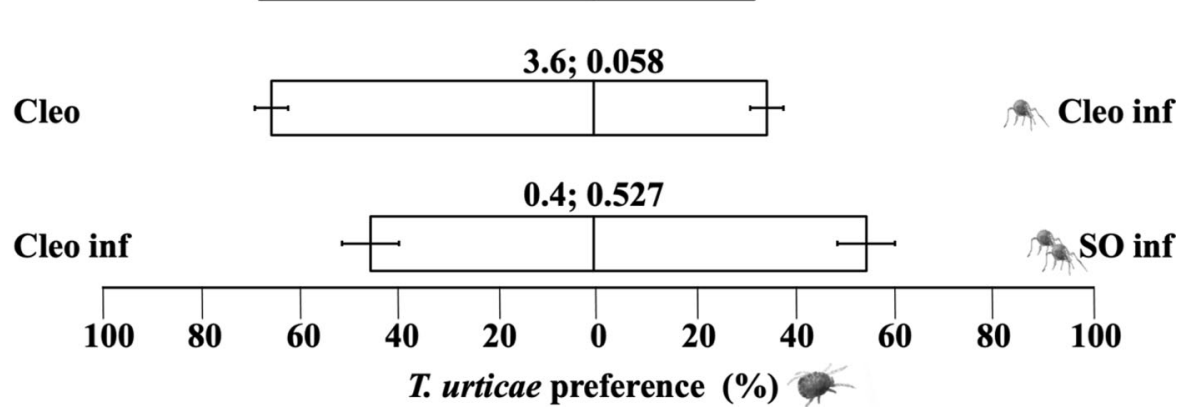

Fig. 1 Olfactory responses (mean \pm SE) of T. urticae gravid females to a $N$. californicus and $\mathbf{b} P$. persimilis. For each phytoseiid species, $T$. urticae had to choose between two odor sources. Four sets of ten females per choice combination were tested. From top to bottom these combinations were: empty glass versus the phytoseiid, sour orange (SO) versus SO-infested

confirmed. To obtain the mesh bags containing 25 females, we followed the same procedure as above. However, females were moved from the black plastic board into the bag $(10 \times 5 \mathrm{~mm})$, which was closed with a magnet, and immediately used as an odor source. When plants infested by phytoseiids were needed, 25 females collected on the black plastic board were regularly distributed on the leaves of the plant. Plants remained in a climatic chamber for $48 \mathrm{~h}$ before use. To prevent ambulatory mite movement between plants, pots were isolated from each other by singly setting them in a tray $(14 \times 14 \times 7 \mathrm{~cm})$, plants (SO inf), Cleopatra mandarin (Cleo) versus Cleo-infested plants (Cleo inf), and Cleo inf versus SO inf. Infested plants had been exposed to 25 phytoseiid gravid females for $48 \mathrm{~h}$ before the onset of the assay. Results were pooled and subjected to $\chi^{2}$ test for a $1: 1$ distribution ( $\chi^{2}$ and $P$-values for each treatment are shown in the figure; df were always one)

placed inside a larger tray filled with water. Plants grouped by genotype and infestation status, were kept isolated to avoid any exposure to plant volatiles from other treatments (Agut et al. 2015).

To assess the number of phytoseiids that remained on the plants during our assays, we carried out a separate experiment where we infested six plants of each genotype with either $N$. californicus or $P$. persimilis as before. Half of these plants were subjected to a destructive sampling $24 \mathrm{~h}$ after infestation, and the remaining half $24 \mathrm{~h}$ later. Plants were cut in pieces and individually placed in a beaker with 
(a) Empty
glass

SO

Cleo
$12.1 ; \leq 0.001$

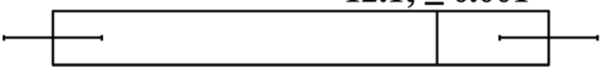

$0.4 ; 0.527$

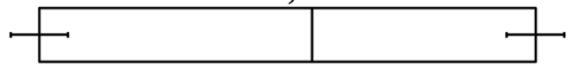

SO inf

\section{N. californicus}

$0.1 ; 0.752$

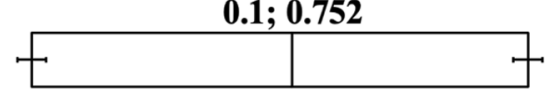

Cleo inf

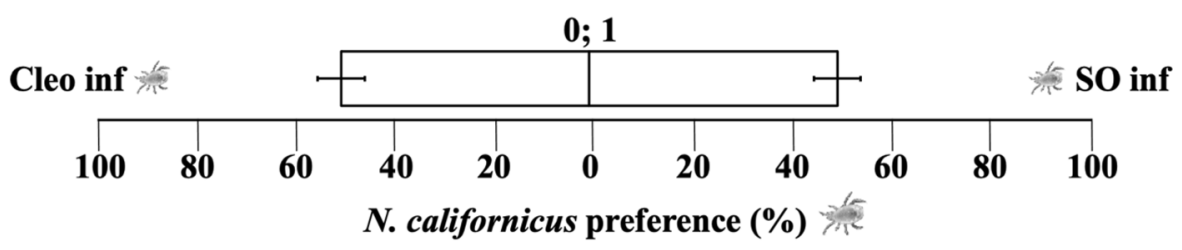

(b)

Empty glass

$0.4 ; 0.527$

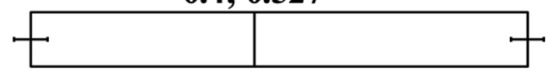

P. persimilis

\section{6; 0.058}

SO

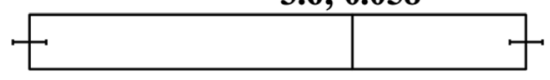

SO inf

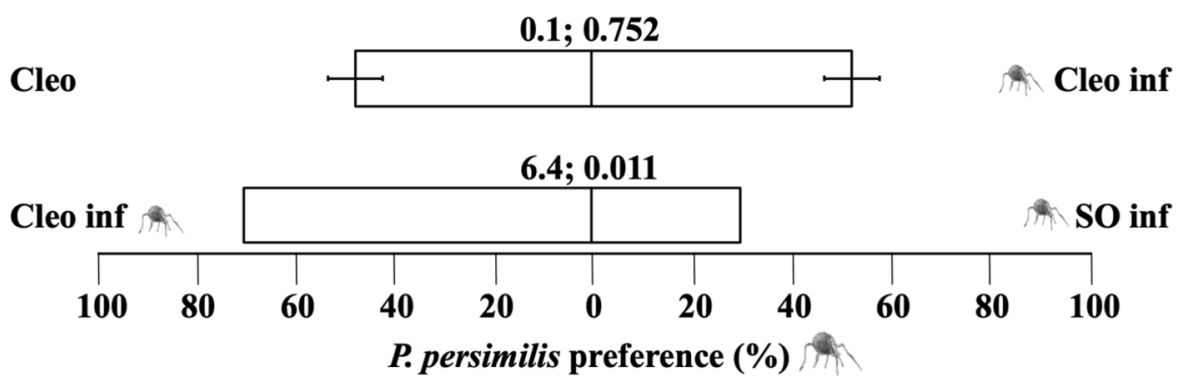

Fig. 2 Olfactory responses (mean $\pm \mathrm{SE}$ ) of a $N$. californicus and $\mathbf{b} P$. persimilis gravid females to conspecific odors. For each phytoseiid species, four different combinations, in which the phytoseiid had to choose between two odor sources, were tested. Four sets of ten females per choice combination were tested. From top to bottom these combinations were: empty glass versus the phytoseiid, sour orange (SO) versus SO-infested

$500 \mathrm{ml}$ of $70 \%$ ethanol and stirred for 10 min with a glass stirring rod. Subsequently, the suspension was poured onto a cellulose nitrate filter with a pore size of $0.45 \mu \mathrm{m}$ (Sartorius Stedim Biotech; Barcelona, Spain) fitted to a filtration unit PSF 500/500 $\mathrm{ml}$ (Thermo Fisher Scientific Inc; Sant Cugat del Vallès, Spain). Phytoseiids (all stages) retained on the filter were counted under a binocular microscope. plants (SO inf), Cleopatra mandarin (Cleo) versus Cleo-infested plants (Cleo inf), and Cleo inf versus SO inf. Infested plants had been exposed to 25 phytoseiid gravid females for $48 \mathrm{~h}$ before the onset of the assay. Results were pooled and subjected to $\chi^{2}$ test for a 1:1 distribution $\left(\chi^{2}\right.$ and $P$-values for each treatment are shown in the figure; df were always one)

\section{Characterization of plant volatiles}

Volatiles from SO and CM plants, including clean and phytoseiid-infested plants (same procedure as above), were collected using a headspace collection system (Agut et al. 2015; Bruinsma et al. 2010; Cruz-Miralles et al. 2019). The same 51 glass vessels and ventilation system used in the Y-tube tests were used. Pasteur pipettes with $300 \mathrm{mg}$ of Porapak (Sigma-Aldrich, Barcelona, Spain) were used as a volatile retention filter. The system was cleaned with acetone and dried 
in an oven $1 \mathrm{~h}$ prior to the assay. Plants, either infested or not, were individually introduced into the glass vessels. Volatiles were collected in $1 \mathrm{ml}$ of ethyl acetate during the following $24 \mathrm{~h}$. Three plants per genotype and infestation status were considered in three different replicates.

An Agilent 6890N Gas Chromatography (GC) system (Palo-Alto, CA, USA), equipped with an Agilent 7683 autosampler, coupled to a time-of-flight mass spectrometer (TOF-MS), GCT (Waters Corp., Manchester, UK), operating in electron ionization (EI) mode was used. A fused silica DB-5MS capillary column of $30 \mathrm{~m}$ length, $0.25 \mathrm{~mm}$ internal diameter and a film thickness of $0.25 \mathrm{~m}$ (J\&W Scientific, Folson, CA, USA) were used for GC separation. The temperature program for this process was the following: $50{ }^{\circ} \mathrm{C}(1 \mathrm{~min}), 5{ }^{\circ} \mathrm{C} \min ^{-1}$ to $210{ }^{\circ} \mathrm{C}(1 \mathrm{~min})$, $20^{\circ} \mathrm{C} \mathrm{min}$ min $^{-1}$ to $300{ }^{\circ} \mathrm{C}(2 \mathrm{~min})$. This resulted in a total analysis run of $40.50 \mathrm{~min}$. Splitless injections were carried out. Helium was used as carrier gas at $1 \mathrm{ml} \mathrm{min}{ }^{-1}$. The interface and source temperatures were both set to $250{ }^{\circ} \mathrm{C}$ and a solvent delay of $3 \mathrm{~min}$ was selected. The TOF-MS was operated at one spectrum $\mathrm{s}^{-1}$ acquiring the mass range $\mathrm{m} / \mathrm{z}, 50-650$ and using a multi-channel plate voltage of $2800 \mathrm{~V}$. The TOF-MS resolution was ca. 8500 (full width at halfmaximum, FWHM) at $\mathrm{m} / \mathrm{z}$ 614. Heptacose, used for the daily mass calibration as well as lock mass, was injected via syringe into the reference reservoir at $30{ }^{\circ} \mathrm{C}$. The $\mathrm{m} / \mathrm{z}$ ion monitored was 218.9856 . The application manager ChromaLynx, a module of MassLynx software, was used to investigate the presence of non-target compounds in the samples. Volatile compounds were tentatively identified using GC-MS and matching to the National Institute of Standards and Technology (NIST\EPAINIH Mass Spectral Library, version 2.0, build 4/2005) using match values of at least 850 as a threshold for identification, as described by Wallis et al. (2008). Furthermore, for each HIPV identified the TOF-MSderived peak areas were calculated and used to estimate their relative concentration.

Quantitative real-time reverse transcriptionpolymerase chain reaction (qRT- PCR) analysis in plants infested by phytoseiids

Different replicates including six plants per citrus genotype were considered for each phytoseiid species/ rearing (three for the commercial rearing and two for the laboratory colony) combination. Three plants were infested with 25 females, whereas the other three remained phytoseiid-free and were used as control. $48 \mathrm{~h}$ later, leaves were cut and immediately introduced into $50 \mathrm{ml}$ Falcon vials, which were immersed in liquid nitrogen and stored at $-80{ }^{\circ} \mathrm{C}$ until extraction. Leaves from the same plant were pulled together in the same vial. RNA was extracted using a Plant RNA protocol with TRIzol (Kiefer et al. 2000) and further processed as in previous studies (Agut et al. 2014; Cabedo-López et al. 2019; Cruz-Miralles et al. 2019). For qRT-PCR experiements, $1 \mu \mathrm{g}$ of total RNA was digested with $0.7 \mu \mathrm{g}$ of DNase (RNase-free DNase I) in $0.7 \mu \mathrm{l}$ for DNase buffer and Mili-Q water up to $4.9 \mu \mathrm{l}$ and incubated for $30 \mathrm{~min}$ at $37{ }^{\circ} \mathrm{C}$. After incubation, $0.7 \mu \mathrm{l}$ of EDTA was added and incubated again at $65^{\circ} \mathrm{C}$ for $10 \mathrm{~min}$ to inactivate DNase (Thermofisher Scientific Inc.). The RT reaction was performed by adding $7 \mu \mathrm{l}$ of DNase reaction, $2 \mu \mathrm{l}$ of PrimeScript buffer and $0.5 \mu \mathrm{l}$ of PrimeScript RT and Oligo-dT respectively (PrimeScript RT Reagent Kit, Takara Bio Inc.). The reaction mixture was incubated at $37{ }^{\circ} \mathrm{C}$ for $15 \mathrm{~min}$. Complementary DNA from the RT reaction, $10 \times$ diluted, was used for qPCR. Forward and reverse primers $(0.3 \mu \mathrm{M})$ were added to $5 \mu \mathrm{l}$ of Maxima SYBR Green qPCR Master Mix, $1 \mu \mathrm{l}$ of cDNA and $3 \mu \mathrm{l}$ Mili-Q sterile water (Maxima SYBR Green/ROX qPCR, Thermofisher Scientific Inc.). qPCR was carried out using a StepOne Instrument (Applied Biosystems) sequence detector with standard PCR conditions $\left(95^{\circ} \mathrm{C}-10 \mathrm{~min}\right.$; $40 \times\left(95{ }^{\circ} \mathrm{C}-10 \mathrm{~s} ; 55^{\circ} \mathrm{C}-10 \mathrm{~s} ; 72{ }^{\circ} \mathrm{C}-20 \mathrm{~s}\right)$; $\left.60{ }^{\circ} \mathrm{C}-10 \mathrm{~s} ; 95^{\circ} \mathrm{C}-15 \mathrm{~s}\right)$. qRT-PCR analysis was replicated three times. The expression of lipoxygenase 2 (LOX2; accession Cit.16756.1.S1_sat; forward primer: $5^{\prime} \rightarrow 3^{\prime}$ GAACCATATTGCCACTTTCG; reverse primer $5^{\prime} \rightarrow 3^{\prime}$ : CGTCATCAATGACTTGACCA), pathogenesis-related protein 5 (PR5; accession BAI63297.1; forward primer: $5^{\prime} \rightarrow 3^{\prime}$ CATCAAGCTTCACAGTGCTTAG; reverse primer $5^{\prime} \rightarrow 3^{\prime}$ : CCACAACGTACAGACTGATGAC) and chalcone synthase $(\mathrm{CHS}$; accession $\mathrm{CF} 417078$; forward primer: $5^{\prime} \rightarrow 3^{\prime}$ : AGACGATCCTCCCTGACTCT; reverse primer $5^{\prime} \rightarrow 3^{\prime}$ : CTCCACTTGGTCCAGAATTG) genes was determined. Relative expression was compared with the housekeeping gene glyceraldehyde 3-phosphate dehydrogenase (GAPDH; accession Cit.122.1; forward 
primer: $5^{\prime} \rightarrow 3^{\prime}$ : GGAAGGTCAAGATCGGAAT-

$\begin{array}{lll}\text { CAA; } & \text { reverse primer } & 5^{\prime} \rightarrow 3^{\prime}: \\ \text { CGTCCCTCTGCAAGATGACTCT). } & \end{array}$

Statistical analysis

Results of each olfactometer test were initially subjected to logistic regression with a logit link function to check for the effect of the set of mites used on each date on mite preference. Lack of significance $(P>0.05)$ was a prerequisite to pool the four sets, which were then subjected to $\chi^{2}$ analysis to test whether they departed from a 1:1 distribution. The TOF-MS-derived peak areas were subjected to ANOVA considering the factors plant genotype, infestation status and their interaction. When necessary, we used Bonferroni post-hoc test for mean separation. The relative expression of JA, SA, and flavonoid signaling pathways homologous marker genes LOX2, PR5 and CHS, respectively, were analyzed in phytoseiid-infested and clean plants and compared using Student $t$-test. IBM SPSS Statistics 23 was used.

\section{Results}

The presence of either $N$. californicus or $P$. persimilis on citrus plants modifies the behavior of conspecifics and their potential prey T. urticae

More than $87 \%$ of the mites used in the olfactometer responded to the tested odors (Supplementary Fig. S1 and S2). Maximum rates of response were observed for $T$. urticae $(92.8 \pm 1.3 \%$; mean $\pm \mathrm{SE})$, followed by $P$. persimilis $(88.9 \pm 2.4 \%)$ and $N$. californicus $(87.0 \pm 2.4 \%)$. To check whether our initial hypothesis that a preeminence of phytoseiid odors would result in the three mite species preferring clean versus phytoseiid-exposed plants, we first tested for each choice test the effect of the set of mites used on each date, which was not significant (Supplemetary Table S1). As a consequence, the results of the four replicates per choice test were pooled and subjected to $\chi^{2}$ tests (Figs. 1, 2). In agreement with our hypothesis, T. urticae gravid females were similarly repelled by $N$. californicus (Fig. 1a) and P. persimilis (Fig. 1b) regardless of whether they were exposed solely to the body odors of the predators $(P<0.027)$ or to those of phytoseiid-exposed plants. Although infested SO proved repellent $(P=0.027)$ and infested $\mathrm{CM}$ triggered a similar but non-significant effect $(P=0.058)$, T. urticae showed no preference for any of these citrus genotypes when both of them had been exposed to these phytoseiids $(P \geq 0.527)$. Remarkably, we were unable to recover any specimen of $P$. persimilis from the plants exposed to this phytoseiid when the choicetests took place, $48 \mathrm{~h}$ after infestation. However, 10-12 adults per plant and no eggs could be recovered $24 \mathrm{~h}$ earlier. Therefore, the observed preferences for $P$. persimilis should be attributed to the traces (e.g., feces) left by this phytoseiid on the plant. In the case of $N$. californicus, $11-15$ adults and 0-2 eggs per plant were found when the choice experiments were performed. These figures were higher (18-20 adults and 0-2 eggs per plant) $24 \mathrm{~h}$ earlier.

None of the phytoseiids was attracted to conspecific body odors. While $N$. californicus preferred clean air to conspecific body odors (Fig. $2 \mathrm{a} ; P<0.001$ ), $P$. persimilis did not show any preference (Fig. 2b; $P=0.527)$. No preeminence of conspecific body odors, though, was observed for $N$. californicus, which did not show any preference when exposed to the three combinations including conspecific-infested plants (Fig. 2a; $P>0.527$ ). On the contrary, when $P$. persimilis had to choose between clean and conspecific-exposed plants, choice depended on plant genotype, with a preference for CM over SO plants (Fig. $2 b ; P=0.011$ ). These contrasting choices highlight the importance of the interaction between plant and mite-associated odors for triggering ambulatory responses in phytoseiids.

$N$. californicus but not $P$. persimilis triggers the production of volatiles in citrus plants

When the volatile metabolome of phytoseiid-exposed relative to clean plants was characterized, we found no differences for $P$. persimilis whereas $N$. californicus generated different blends depending on the citrus species considered. This result may be related to the escape of $P$. persimilis from infested plants, as reported in the Y-tube assays. Keep in mind though that volatile collection took place during the $24 \mathrm{~h}$ after infestation, when 10-12 adult $P$. persimilis were still present on the plant. From the ten compounds differentially produced upon exposure to $N$. californicus (Table 1, Fig. 3), seven were observed in one 
Citrus species only. Two of them appeared in CM plants only and did not change with infestation: 2-methyl-3-heptanone and bezaldehyde. Likewise, 6-benzoyloxy-3,4-dimethyl-coumarin and 1-ethyl-3(1-methylethyl)-benzene were detected in SO plants only and did not change with infestation. Contrarily, 1,4-diethyl-benzene and 1,15-pentadecanedioic acid appeared in SO only and increased with infestation, and 1,2-benzisothiazole decreased with infestation in this genotype only. The remaining three compounds: cineole, 1-phenyl-1-hexanone, and 3,4-dimethylbezamide were higher in SO and increased with infestation.

\section{$N$. californicus triggers defensive responses in citrus}

The different volatile blends observed for $N$. californicus could be related to the activation of different defensive pathways in SO and CM plants upon infestation. Remarkably, the same patterns were observed irrespective of the immediate origin of the tested mites (commercial and laboratory colonies) (Table 2). Both the JA marker LOX2 and the flavonoids marker $C H S$ genes were downregulated in SO with infestation while the SA marker PR5 did not change (Table 2). Contrarily, the JA marker LOX2 gene was upregulated in $\mathrm{CM}$ with infestation while $P R 5$ and CHS genes remained unchanged (Table 2). None of these genes was induced by $P$. persimilis. This result is coherent with the lack of differences observed in the volatile metabolome of clean relative to $P$. persimilis-exposed citrus plants.

\section{Discussion}

Plant defense against herbivores has been mostly attributed to either mechanical feeding damage or herbivory-derived elicitors found in the oral secretions of the herbivore (Hilker and Meiners 2010; Schuman and Baldwin 2016), to both of them, or to other herbivory-related secretions (i.e., aphid honeydew; Schwartzberg and Tumlinson 2014). Although $N$. californicus does not engage in direct plant-feeding (Cruz-Miralles et al. 2021), our results show that this species interacts with plant defense in a plant-genotype specific manner (Table 2). Therefore, triggers different from plant feeding occur in $N$. californicus. As, contrary to $N$. californicus, it was not possible to maintain $P$. persimilis on plants during the whole study period (i.e., $48 \mathrm{~h}$ for the genetic analyses), whether this species may be able to elicit this type of responses remains an unsolved question. Because the only way to force this specialist predator to stay on plants would require previous infestation with $T$. urticae, it will be extremely difficult to address this question. Our results, though, prove that plant defense triggered by phytoseiids (1) may be related to activities different from direct plant feeding, (2) is speciesspecific and (3) depends on plant genotype. These issues are discussed below.

Plant defense triggered by phytoseiids may be related to activities different from plant feeding

As phytoseiids lack a specialized ovipositor, they cannot insert their eggs into the plant tissue. Therefore, touch and touch-associated secretions, like walking and oviposition, are the most likely triggers of the responses observed. Although the nature of the secretions that phytoseiids produce when walking and ovipositing remains largely ignored, in our experiments successful oviposition was observed in plants exposed to $N$. californcus. Therefore, eggs could be the trigger for the responses observed. However, as not all plants infested with $N$. californicus showed eggs (the number of eggs per plant ranged from zero to two), further research is needed to confirm this hypothesis. Because in our assays $P$. persimilis gradually abandoned the plant during the assays, another possible explanation for our results could be related to the conspicuous differences in the morphology and size of the legs of $N$. californicus and E. stipulatus compared to $P$. persimilis (AthiasHenriot 1960; Beaulieu and Beard 2018; Croft et al. 1999; Okassa et al. 2010). These differences, together with species-specific chetotaxy, could explain why, contrary to E. stipulatus (Cabedo-López et al. 2019) and $N$. californicus, $P$. persimilis did not trigger plant defense. Same as before, though, further research is needed.

Plant defense triggered by phytoseiids is speciesspecific and depends on plant genotype

Landing, walking and oviposition by an herbivorous arthropod on a host plant is a reliable indicator for an upcoming herbivory (Bandoly and Steppuhn 2016). 
Therefore, plants using these activities as either a trigger for induced defense (Hilker and Fatouros 2015; $\mathrm{Wu}$ and Baldwin 2010) or a priming signal to boost particular feeding-induced defense traits (Conrath 2011) could be expected. The reactions observed in $\mathrm{CM}$ plants to $N$. californicus could, therefore, be related to this genotype mistakenly identifying the predator as a potential threat or as an indication of the presence of herbivores, which pose a risk to plants (Helms et al. 2019). The upregulation of LOX2 in CM by $N$. californicus was one order of magnitude lower than that elicited by T. urticae in SO (Agut et al. 2014) and similar to that triggered by E. stipulatus in $\mathrm{SO}$ and CM plants (Cabedo-López et al. 2019). E. stipulatusinfested plants, though, were attractive to $T$. urticae (Cruz-Miralles et al. 2019). T. urticae avoidance of plants exposed to predators has been repeatedly documented (Fernández-Ferrari and Schausberger 2013; Grostal and Dicke 1999, 2000; Hackl and Schausberger 2014; Pallini et al. 1999; Škaloudová et al. 2007). Accordingly, citrus plants either infested by $N$. californicus or previously exposed to $P$. persimilis proved repellent for T. urticae (Fig. 1).

Cineole may play a crucial role for in $T$. urticae plant choices

Only one compound out of the six volatiles differentially produced by SO and CM plants when exposed to N. californicus, namely cineole (Table 2, Fig. 3h), was also found when examining the response of the same Citrus spp. to E. stipulatus (Cruz-Miralles et al. 2019). However, contrary to $N$. californicus, infestation by $E$. stipulatus decreased the emission of this compound. Therefore, this terpenoid may play a crucial role in $T$. urticae plant choices and could explain attraction to $E$. stipulatus-infested plants (Cruz-Miralles et al. 2019) but repellence to $N$. californicus-infested plants (Fig. 1a). Consequently, cineole deserves further studies as it could prove useful to manipulate $T$. urticae populations. As two additional volatiles showed the same trend as cineole upon $N$. californicus infestation (1-phenyl-1-hexanone and 3,4-dimethylbezamide), their involvement in the observed results cannot be excluded (Gregg et al. 2018). It has to be noted that this type of results may change depending on the context (Fernández Ferrari and Schausberger 2013; Pallini et al. 1999; Zhang and Sanderson 1992).
Phytoseiid-related odors modulate host selection by $T$. urticae

As pointed out earlier, T. urticae responded to the different odor sources used in our behavioral assays as expected (i.e., attraction to less defended plants and repellence for phytoseiid body odors). Remarkably, as $\mathrm{CM}$ was preferred over $\mathrm{SO}$ when both plants were clean (Cabedo-López et al. 2019) but no preference was observed when they were infested by phytoseiids (Fig. 1), these results can be taken as evidence of a preeminence of phytoseiid-related odors for host selection by $T$. urticae. Similar results had been observed in previous studies involving T. urticae (Agut et al. 2015) and E. stipulatus (Cruz-Miralles et al. 2019). The upregulation of LOX2 in CM observed upon $N$. californicus infestation (Table 2) may have reinforced the preference for clean plants of this genotype, which were relatively less defended than infested ones (Fig. 2a). However, the opposite did not occur for SO although both LOX2 and CHS were downregulated (and therefore these plants became less defended in terms of direct defense) upon $N$. californicus infestation (Table 2). This result highlights the important effect of the odors related to the presence, either actual or previous, of these two phytoseiids for $T$. urticae. This effect would also explain the behavior of $T$. urticae when exposed to $P$. persimilis (Fig. 1b) and this is not surprising as these volatiles should be reliable indicators of predator presence (i.e., indirect defense) and, therefore, of an imminent predation risk (Fernández Ferrari and Schausberger 2013; Pallini et al. 1999; Zhang and Sanderson 1992).

The interaction between plant and phytoseiidrelated odors are key for phytoseiid ambulatory responses

In the case of phytoseiids, some of our initial hypotheses had to be rejected. When $N$. californicus and $P$. persimilis responded to conspecific-infested plants, choices did not follow the rationale of choosing less defended plants to avoid cannibalism. The strong repellence observed in $N$. californicus for conspecific body odors disappeared when this phytoseiid was present in citrus (Fig. 2a), whereas the neutral role played by $P$. persimilis body odors when offered alone affected choice when combined with citrus odors 

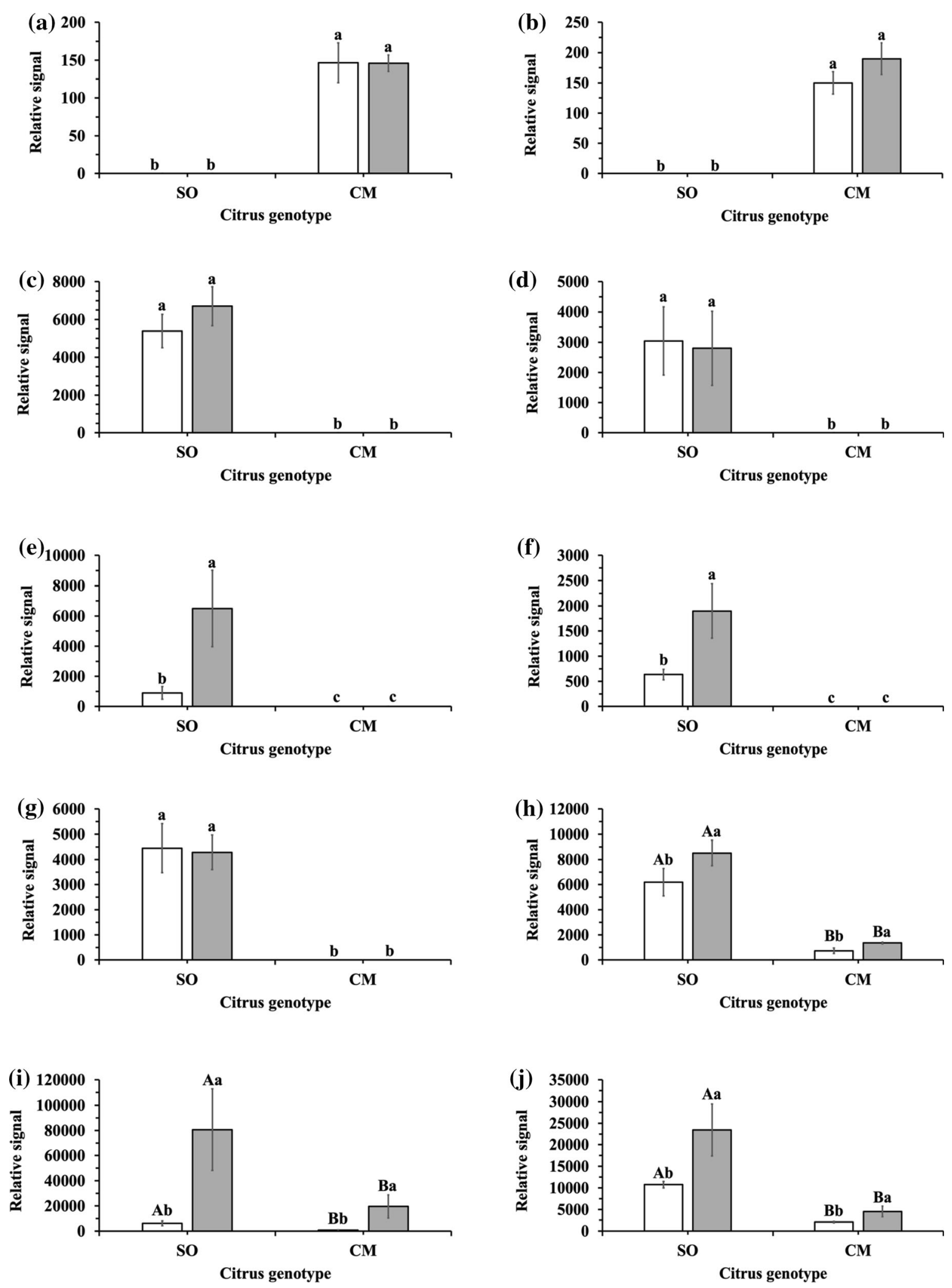
४Fig. 3 Relative signal (TOF-MS-derived peak areas; mean \pm $\mathrm{SE}$ ) of the volatiles differentially produced by infested (grey bars) and clean (white bars) sour orange (SO) and Cleopatra mandarin $(\mathrm{CM})$ plants during the first $24 \mathrm{~h}$ of infestation with $25 \mathrm{~N}$. californicus gravid females. a 2-methyl-3-heptanone; b benzaldehyde; c 6-benzyloxy-3,4-dihydro-4,4-dimethyl-coumarin; d 1-ethyl-3-(1-methylethyl)-benzene; e 1,4-diethyl-benzene; f 1,15-pentadecanedioic acid; g 1,2-benzisothiazole; h cineole; i 1-phenyl-1-hexanone; j 3,4-dimethylbenzamide. For each figure, bars with the same letter(s) are not significantly different (ANOVA, $P>0.05$ ). When both plant genotype and infestation status were significant but their interaction was not (Table 1), upper-case letters refer to genotype and lower-case to infestation
(Fig. 2b). Interestingly, Janssen et al. (1997) had observed that $P$. persimilis uses volatiles to avoid prey patches with conspecifics although both conspecifics and prey alone on bean leaves were attractive. A similar situation was observed for E. stipulatus (CruzMiralles et al. 2019). Therefore, these results point at a highly relevant interaction between plant and phytoseiid own odors for phytoseiid choices. Furthermore, our results show that the interspecific variations in foraging responses of phytoseiids to prey- and

Table 1 Volatile profiling in the headspace of sour orange (SO) and Cleopatra mandarin (Cleo) plants either clean or infested (inf)

\begin{tabular}{|c|c|c|c|}
\hline \multirow[t]{2}{*}{ Volatile compound } & \multicolumn{3}{|l|}{ Statistics $(F ; \mathrm{df} ; P)$} \\
\hline & Plant genotype (A) & $\begin{array}{l}\text { Infestation status } \\
\text { (B) }\end{array}$ & $A \times B$ \\
\hline 2-Methyl-3-heptanone & $\begin{array}{l}118.54 ; 1 \\
32 ;<0.001 \\
\text { SO }<\text { Cleo }\end{array}$ & $\begin{array}{l}<0.01 ; 1,32 \\
0.980 \\
\text { Clean }=\text { inf }\end{array}$ & $<0.01 ; 1,32 ; 0.980$ \\
\hline Benzaldehyde & $\begin{array}{l}127.15 ; 1 \\
32 ;<0.001 \\
\text { SO }<\text { Cleo }\end{array}$ & $\begin{array}{l}1.75 ; 1,32 ; 0.195 \\
\text { Clean }=\text { inf }\end{array}$ & $1.75 ; 1,32 ; 0.195$ \\
\hline $\begin{array}{l}\text { 6-Benzyloxy-3,4-dihydro-4,4-dimethyl- } \\
\text { coumarin }\end{array}$ & $\begin{array}{l}88.91 ; 1 \\
32 ;<0.001 \\
\text { SO }>\text { Cleo }\end{array}$ & $\begin{array}{l}1.05 ; 1,32 ; 0.314 \\
\text { Clean }=\text { inf }\end{array}$ & $1.05 ; 1,32 ; 0.314$ \\
\hline 1-Ethyl-3-(1-methylethyl)-benzene & $\begin{array}{l}13.89 ; 1 \\
32 ;<0.001 \\
\text { SO }>\text { Cleo }\end{array}$ & $\begin{array}{l}0.02 ; 1,32 ; 0.877 \\
\text { Clean }=\text { inf }\end{array}$ & $0.02 ; 1,32 ; 0.877$ \\
\hline 1,4-Diethyl-benzene & $\begin{array}{l}9.40 ; 1,32 ; 0.004 \\
\mathrm{SO}>\text { Cleo }\end{array}$ & $\begin{array}{l}5.38 ; 1,32 ; 0.027 \\
\text { Clean }<\text { inf }\end{array}$ & $\begin{array}{l}5.38 ; 1,32 ; 0.027 \\
\text { SO inf }>\text { SO clean }>\text { Cleo inf }=\text { Cleo } \\
\text { clean }\end{array}$ \\
\hline 1,15-Pentadecanedioic acid & $\begin{array}{l}23.79 ; 1 \\
32 ;<0.001 \\
\text { SO }>\text { Cleo }\end{array}$ & $\begin{array}{l}5.92 ; 1,32 ; 0.021 \\
\text { Clean }<\text { inf }\end{array}$ & $\begin{array}{l}5.92 ; 1,32 ; 0.021 \\
\text { SO inf }>\text { SO clean }>\text { Cleo inf }=\text { Cleo } \\
\text { clean }\end{array}$ \\
\hline 1,2-Benzisothiazole & $\begin{array}{l}60.34 ; 1 \\
32 ;<0.001 \\
\mathrm{SO}>\text { Cleo }\end{array}$ & $\begin{array}{l}0.02 ; 1,32 ; 0.883 \\
\text { Clean }=\text { inf }\end{array}$ & $0.02 ; 1,32 ; 0.883$ \\
\hline Cineole & $\begin{array}{l}80.94 ; 1 \\
28 ;<0.001 \\
\text { SO }>\text { Cleo }\end{array}$ & $\begin{array}{l}4.42 ; 1,28 ; 0.045 \\
\text { Clean }<\text { inf }\end{array}$ & $1.48 ; 1,28 ; 0.234$ \\
\hline 1-Phenyl-1-hexanone & $\begin{array}{l}4.39 ; 1,32 ; 0.044 \\
\text { SO }>\text { Cleo }\end{array}$ & $\begin{array}{l}8.59 ; 1,32 ; 0.006 \\
\text { Clean }<\text { inf }\end{array}$ & $3.07 ; 1,32 ; 0.089$ \\
\hline 3,4-Dimethylbenzamide & $\begin{array}{l}22.16 ; 1 \\
32 ;<0.001 \\
\text { SO }>\text { Cleo }\end{array}$ & $\begin{array}{l}6.65 ; 1,32 ; 0.015 \\
\text { Clean }<\text { inf }\end{array}$ & $3.05 ; 1,32 ; 0.090$ \\
\hline
\end{tabular}

For each volatile, TOF-MS-derived peak areas were compared using ANOVA considering the factors plant genotype, infestation status, and their interaction. Bonferroni procedure was used for mean separation when needed. Volatiles were tentatively identified by comparing to the National Institute of Standards and Technology (NIST) Library as described by Wallis et al. (2008) 
Table 2 Relevance of lypoxygenase 2, LOX2 (cit16759.1S1), pathogenesis-related protein 5, PR5 (BAI63287.1), and chalcone synthase, CHS (CF417078) triggered by $N$. californicus in either sour orange or Cleopatra mandarin

\begin{tabular}{|c|c|c|c|}
\hline \multirow[t]{2}{*}{ Gene marker } & \multicolumn{2}{|c|}{ Relative gene expression } & \multirow[t]{2}{*}{ Student $t$-test $(t ; \mathrm{df} ; P)$} \\
\hline & Clean & Infested & \\
\hline \multicolumn{4}{|l|}{ Sour orange } \\
\hline \multicolumn{4}{|c|}{ Koppert Biological Systems } \\
\hline$L O X 2$ & $0.371 \pm 0.106$ & $0.133 \pm 0.016$ & $2.383 ; 8 ; 0.044$ \\
\hline PR5 & $0.263 \pm 0.074$ & $0.209 \pm 0.026$ & $0.995 ; 8 ; 0.349$ \\
\hline $\mathrm{CHS}$ & $0.087 \pm 0.019$ & $0.034 \pm 0.003$ & $3.384 ; 8 ; 0.010$ \\
\hline \multicolumn{4}{|l|}{ Laboratory } \\
\hline$L O X 2$ & $0.082 \pm 0.006$ & $0.065 \pm 0.012$ & $2.576 ; 5 ; 0.005$ \\
\hline PR5 & $0.150 \pm 0.022$ & $0.110 \pm 0.031$ & $2.373 ; 5 ; 0.064$ \\
\hline $\mathrm{CHS}$ & $3.548 \pm 0.137$ & $1.799 \pm 0.771$ & $2.688 ; 5 ; 0.043$ \\
\hline \multicolumn{4}{|c|}{ Cleopatra mandarin } \\
\hline \multicolumn{4}{|c|}{ Koppert Biological Systems } \\
\hline$L O X 2$ & $0.756 \pm 0.061$ & $1.376 \pm 0.133$ & $3.850 ; 8 ; 0.005$ \\
\hline PR5 & $0.136 \pm 0.015$ & $0.124 \pm 0.047$ & $0.317 ; 8 ; 0.759$ \\
\hline $\mathrm{CHS}$ & $0.198 \pm 0.013$ & $0.183 \pm 0.056$ & $0.268 ; 8,0.795$ \\
\hline \multicolumn{4}{|l|}{ Laboratory } \\
\hline$L O X 2$ & $0.015 \pm 0.001$ & $0.118 \pm 0.037$ & $2.969 ; 5 ; 0.031$ \\
\hline PR5 & $0.026 \pm 0.005$ & $0.060 \pm 0.025$ & $1.270 ; 5 ; 0.260$ \\
\hline $\mathrm{CHS}$ & $1.760 \pm 0.390$ & $0.573 \pm 0.271$ & $2.078 ; 5 ; 0.093$ \\
\hline
\end{tabular}

Specimens used in these assays were originally obtained from Koppert Biological Systems and either directly used or reared for several generations on clementine leaves in our laboratory before use. Data are presented as a mean \pm SE of transcript expression relative to the housekeeping gene GAPDH (Cit.122.1). Significant differences between infested and clean plants were estimated performing different Student $t$-tests for each gene and mite origin

predator-associated stimuli described by Zhang and Sanderson (1992), are also dependent on plant genotype.

To sum up, our results prove that the outcome of citrus-phytoseiid interactions is species-specific and affected by plant genotype. Whether these differences should be attributed to direct plant feeding (i.e., for $E$. stipulatus) or to other activities (i.e., N. californicus) deserves further research. A better understanding of the system could be used to refine current crop protection practices. By exploiting the semiochemicals involved, like cineole or those related to the traces left by $P$. persimilis, which seem to play a crucial role for $T$. urticae in citrus, the overall efficacy of biological control could be enhanced. Likewise, as $N$. californicus is one of the top species of biological control agents commercially produced and used worldwide in augmentative biological control (van Lenteren 2012), further studies aimed at determining whether the plant defense induction observed in citrus occurs in other crop plants and how this may affect prey beyond predation are needed.

Acknowledgements This study was partially funded by MINECO (AGL2014-55616-C3; AGL2015-649902R; RTI2018-094350-B-C33). We thank M. Piquer (UJI) and UJI Servei Central d'Instrumentació Científica (SICI) for technical assistance and J. Calvo (Koppert Biological Systems) for the supply of $N$. californicus. MC received a predoctoral fellowship from MINECO (BES-2015-074570) and MP was the recipient of a research fellowship from INIA (subprogram DOC INIA-CCAA). M. Montserrat (EELM-CSIC) and L. Zappalà (University of Catania) provided useful comments on an earlier draft of this manuscript.

Author contributions JJ and VF designed the assays, which were performed by JC, MC and MG. All authors analyzed the results and contributed to the writing of the manuscript.

Funding The funding was supported by Ministerio de Economía y Competitividad (MINECO): research grants AGL2014-55616-C3 to JAJ and AGL2015-64990- 
2R and RTI2018-094350-B-C33 to VF; pre-doctoral grant BES-2015-074570 to MCL and post-doctoral grant from subprogram DOC INIA-CCAA to MPH.

Data availability Raw data not provided in the supplementary online material deposited in UJI Public Digital Repository.

\section{Compliance with ethical standards}

Conflict of interest Authors declare that they have no conflict of interest to disclose.

Open Access This article is licensed under a Creative Commons Attribution 4.0 International License, which permits use, sharing, adaptation, distribution and reproduction in any medium or format, as long as you give appropriate credit to the original author(s) and the source, provide a link to the Creative Commons licence, and indicate if changes were made. The images or other third party material in this article are included in the article's Creative Commons licence, unless indicated otherwise in a credit line to the material. If material is not included in the article's Creative Commons licence and your intended use is not permitted by statutory regulation or exceeds the permitted use, you will need to obtain permission directly from the copyright holder. To view a copy of this licence, visit http://creativecommons.org/licenses/by/4.0/.

\section{References}

Aguilar-Fenollosa E, Ibáñez-Gual MV, Pascual-Ruiz S, Hurtado M, Jacas JA (2011) Effect of ground-cover management on spider mites and their phytoseiid natural enemies in clementine mandarin orchards (I): bottom-up regulation mechanisms. Biol Control 59:158-170

Agut B, Gamir J, Jacas JA, Hurtado M, Flors V (2014) Different metabolic and genetic responses in citrus may explain relative susceptibility to Tetranychus urticae. Pest Manag Sci 70:1728-1741

Agut B, Gamir J, Jaques JA, Flors V (2015) Tetranychus urticae-triggered responses promote genotype-dependent conspecific repellence or attractiveness in citrus. New Phytol 207:790-804

Athias-Henriot C (1960) Nouveaux Amblyseius d'Algérie (Parasitiformes, Phytoseiidae). Acarologia 2:288-299

Bandoly M, Steppuhn A (2016) A push-button: Spodoptera exigua oviposition on Nicotiana attenuate dose-independently primes the feeding-induced plant defense. Plant Signal Behav 11(1):e1114198

Beaulieu F, Beard JJ (2018) Acarine biocontrol agents Neoseiulus californicus sensu Athias-Henriot (1977) and $N$. barkeri Hughes (Mesostigmata: Phytoseiidae) redescribed, their synonymies assessed, and the identity of $N$. californicus (McGregor) clarified based on examination of types. Zootaxa 4500:451-507

Bruessow F, Asins MJ, Jacas JA, Urbaneja A (2010) Replacement of CTV-susceptible sour orange rootstock by CTVtolerant ones may have triggered outbreaks of Tetranychus urticae in Spanish citrus. Agric Ecosyst Environ 137:93-98

Bruin J, Dicke M, Sabelis MW (1992) Plants are better protected against spider-mites after exposure to volatiles from infested conspecifics. Experientia 48:525-529

Bruinsma M, van Broekhoven S, Poelman EH, Posthumus MA, Müller MJ, van Loon JJJA, Dicke M (2010) Inhibition of lipoxygenase affects induction of both direct and indirect plant defences against herbivorous insects. Oecologia 162:393-404

Cabedo-López M, Cruz-Miralles J, Vacas S, Navarro-Llopis V, Pérez-Hedo M, Flors V, Jaques JA (2019) The olfactive responses of Tetranychus urticae natural enemies in citrus depend on plant genotype, prey presence, and their diet specialization. J Pest Sci 92:1165-1177

Conrath U (2011) Molecular aspects of defence priming. Trends Plant Sci 16:524-531

Croft BA, Luh H, Schausberger P (1999) Larval size relative to larval feeding, cannibalism of larvae, egg or adult female size and larval-adult setal patterns among 13 phytoseiid mite species. Exp Appl Acarol 23:599-610

Cruz-Miralles J, Cabedo-López M, Pérez-Hedo M, Flors V, Jaques JA (2019) Zoophytophagous mites can trigger plant-genotype specific defensive responses affecting potential prey beyond predation: the case of Euseius stipulatus and Tetranychus urticae in citrus. Pest Manag Sci 75:1962-1970

Cruz-Miralles J, Cabedo-López M, Guzzo M, Ibañez-Gual MV, Flors V, Jaques JA (2021) Plant-feeding may explain why the generalist predator Euseius stipulatus does better on less defended citrus plants but Tetranychus sp.-specialists Neoseiulus californicus and Phytoseiulus persimilis do not. Exp Appl Acarol. https://doi.org/10.1007/s10493-02000588-x

De Puysseleyr V, Höfte M, de Clercq P (2011) Ovipositing Orius laevigatus increase tomato resistance against Frankliniella occidentalis feeding by inducing the wound response. Arthropod-Plant Interact 5:71-80

Fernández Ferrari MC, Schausberger P (2013) From repulsion to attraction: species- and spatial context-dependent threat sensitive response of the spider mite Tetranychus urticae to predatory mite cues. Naturwissenschaften 100:541-549

Ferragut FJ, Comelles JC, Mari FG, Marzal C, Roca R, Laborda R (1988) Dinámica poblacional del fitoseido Euseius stipulatus (Athias-Henriot) y su presa Panonychus citri (McGregor) (Acari: Phytoseiidae, Tetranychidae), en los cítricos españoles. Bol San Veg Plagas 14:45-54

Freinschlag J, Schausberger P (2016) Predation risk-mediated maternal effects in the two-spotted spider mite, Tetranychus urticae. Exp Appl Acarol 69:35-47

Gregg PC, Del Socorro AP, Landolt PJ (2018) Advances in attract-and-kill for agricultural pests: beyond pheromones. Annu Rev Entomol 63:453-470

Grostal P, Dicke M (1999) Direct and indirect cues of predation risk influence behavior and reproduction of prey: a case for acarine interactions. Behav Ecol 10:422-427

Grostal P, Dicke M (2000) Recognising one's enemies: a functional approach to risk assessment by prey. Behav Ecol Sociobiol 47:258-264

Hackl T, Schausberger P (2014) Learned predation risk management by spider mites. Front Ecol Evol 2:58 
Helms AM, Ray S, Matulis NL, Kuzemchak MC, Grisales W, Tooker JF, Ali JG (2019) Chemical cues linked to risk: Cues from below-ground natural enemies enhance plant defences and influence herbivore behaviour and performance. Funct Ecol 33:798-808

Hilker M, Fatouros NE (2015) Plant responses to insect egg deposition. Annu Rev Entomol 60:493-515

Hilker M, Meiners T (2010) How do plants "notice" attack by herbivorous arthropods? Biol Rev 85:267-280

Janssen A, Bruin J, Jacobs G, Schraag R, Sabelis MW (1997) Predators use volatiles to avoid prey patches with conspecifics. J Anim Ecol 66:223-232

Karban R (2019) The ecology and evolution of induced responses to herbivory and how plants perceive risk. Ecol Entomol 45:1-9

Kiefer E, Heller W, Ernst D (2000) A simple and efficient protocol for isolation of functional RNA from plant tissues rich in secondary metabolites. Plant Mol Biol Rep 18:33-39

McMurtry JA, Croft BA (1997) Life-styles of phytoseiid mites and their roles in biological control. Annu Rev Entomol 42:291-321

McMurtry JA, De Moraes GJ, Sourassou NF (2013) Revision of the lifestyles of phytoseiid mites (Acari: Phytoseiidae) and implications for biological control strategies. Syst Appl Acarol 18:297-320

Messelink GJ, Bloemhard CMJ, Hoogerbrugge H, van Schelt J, Ingegno BL, Tavella L (2015) Evaluation of mirid predatory bugs and release strategy for aphid control in sweet pepper. J Appl Entomol 139:333-341

Okassa M, Tixier M-S, Kreiter S (2010) Morphological and molecular diagnostics of Phytoseiulus persimilis and Phytoseiulus macropilis (Acari: Phytoseiidae). Exp Appl Acarol 52:291-303

Pallini A, Janssen A, Sabelis MW (1999) Spider mites avoid plants with predators. Exp Appl Acarol 23:803-815

Pappas ML, Steppuhn A, Geuss D, Topalidou N, Zografou A, Sabelis MW, Broufas GD (2015) Beyond predation: The zoophytophagous predator Macrolophus pygmaeus induces tomato resistance against spider mites. PLoS ONE 10(5): 0127251

Perdikis D, Fantinou A, Lykouressis D (2011) Enhancing pest control in annual crops by conservation of predatory Heteroptera. Biol Control 59:13-21

Pérez-Sayas C, Pina T, Gómez-Martínez MA, Camañes G, Ibáñez-Gual MV, Jaques JA, Hurtado Ruiz MA (2015) Disentangling mite predator-prey relationships by multiplex PCR. Mol Ecol Res 15:1330-1345

Pina T, Argolo PS, Urbaneja A, Jaques JA (2012) Effect of pollen quality on the efficacy of two different life-style predatory mites against Tetranychus urticae in citrus. Biol Control 61:176-183

Schuman MC, Baldwin IT (2016) The layers of plant responses to insect herbivores. Annu Rev Entomol 61:373-394

Schwartzberg EG, Tumlinson JH (2014) Aphid honeydew alters plant defence responses. Funct Ecol 28:386-394

Škaloudová B, Zemek R, Křivan V (2007) The effect of predation risk on an acarine system. Anim Behav 74:813-821

van Lenteren JC (2012) The state of commercial augmentative biological control: plenty of natural enemies, but a frustrating lack of uptake. BioControl 57:1-20

Vela JM, Wong E, Jaques JA, Ledesma C, Boyero JR (2017) Mite diversity (Acari: Tetranychidae, Tydeidae, Iolinidae, Phytoseiidae) and within-tree distribution in citrus orchards in southern Spain, with special reference to Eutetranychus orientalis. Exp Appl Acarol 73:191-207

Wallis C, Eyles A, Chorbadjian R, McSpadden Gardener B, Hansen R, Cipollini D, Herms DA, Bonello P (2008) Systemic induction of phloem secondary metabolism and its relationship to resistance to a canker pathogen in Austrian pine. New Phytol 177:767-778

Wu J, Baldwin IT (2010) New insights into plant responses to the attack from insect herbivores. Annu Rev Genet 44:1-24

Zhang ZQ, Sanderson JP (1992) Effects of host plant experience on foraging behavior of the predatory mite Phytoseiulus persimilis (Acari: Phytoseiidae). Ann Entomol Soc Am 85:775-783 